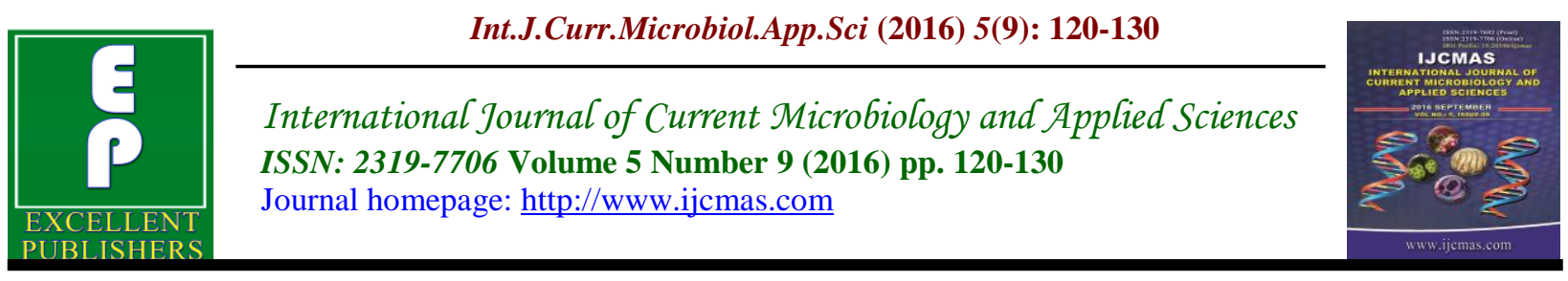

Original Research Article

http://dx.doi.org/10.20546/ijcmas.2016.509.014

\title{
Resins as a Preservative for Fruits and Vegetables
}

\author{
D. Yuvaraj, B. Suvasini* and R. Fouziya \\ Vel Tech High Tech Dr. Rangarajan Dr. Sakunthala Engineering College, Avadi, India \\ *Corresponding author
}

\begin{abstract}
A B S T R A C T
Keywords

Differential scanning calorimetry, Thermogravimetry, Prunus amygdalus dulcis, Acacia nilotica.

Article Info

Accepted:

08 August 2016

Available Online:

10 September 2016

The shelf life period is the main criteria for every food to be fresh and edible for consumption. The main objective of this study is to enhance the durability of fruits so as to store the fruits fresh, import and export without getting spoiled by atmospheric pathogens, moisture, etc which are the route cause for food spoilage. The resins of Prunus amygdalus dulcis and Acacia nilotica were analysed to use as an alternative to waxes that are being coated for preservation. Differential scanning calorimetric analysis and thermogravimetry analysis of the resins showed the stability and degradation of the resins. Results show that resins were stable up to $270-280^{\circ} \mathrm{C}$ and hence climatic temperatures will not have any effect on the resins coated on the fruits. Toxicity studies were performed to check the safe levels of the resins and the resins of Prunus amygdalus dulcis and Acacia nilotica possessed $0 \%$ and $10 \%$ mortality respectively. The fruits were coated with the resins to check their activity to increase their shelf life. It was observed that the fruits coated with Prunus dulcis gum were more desirable compared to those coated with Acacia nilotica gum.
\end{abstract}

\section{Introduction}

Natural tree gums have been collected and coated for improving the quality and enhancing the shelf life of fruits and vegetables without the use of harmful synthetic chemicals.

The absence of post harvest techniques to preserve fresh quality leads to deterioration. The natural waxy coat is not adequate to offer protection against water loss and high respiration rate. In order to prolong the life of fruit / vegetable, rate of respiration has to be restricted and moisture loss should be inhibited, so as to maintain the vital food elements and the same quality as in the freshly picked fruit or vegetable. The contemporary methodology of fruit and vegetable preservation is through the use of edible wax coatings to retain freshness (Ogbe et al., 2012; Adel et al., 2014), to inhibit mold growth and to prevent other physical damage and disease. Though these wax coatings are edible, they pose health hazards to the consumers. Food was once a source of sustenance for life on earth, but conversely, it has made people accessible to the devious fringes, periphery and environs of health hazards. The frequent and constant 
use of fertilizers, chemicals and pesticides to multiply crop production, emanates adverse health effects to the consumers. Added to this is the use of chemical preservatives to increase the shelf life of the fruits and vegetables. These chemical preservatives have adverse side effects on the consumers. Fumigation of food has also been done using Ethylene Di bromide, methyl bromide, Ethylene Oxide. Fumigation by Ethylene Di bromide has been banned by the US environmental protection agency (James, 2003).

Recent techniques to prolong the life of fruits and vegetables have involved the use of wax coating on them. Though there are natural waxes commercially available, they do not coat the fruits and vegetables completely with natural waxes. They prepare edible coatings with the blend of both natural and synthetic waxes which will seem fresh to the consumers but are artificial compounds and will cause various health problems. The augmenting awareness among the public on the use of wax coatings and its side effects has stimulated them to go in search of organic fresh fruits and vegetables, so as to inhibit the passage of noxious and obtrusive elements entering the bloodstream. This has lead to the dramatic increase in the prices of organic crops, and we are oblivious if they are really farm fresh and produced without the use of any chemical fertilizers. In order to overcome the usage of wax and provide a frugal alternative, this work has been undertaken.

\section{Prunus amygdalus dulcis gum/ Almond gum}

Almond gum (secreted by the Prunus amygdalus dulcis/almond tree is sweet almond belonging to the family Rosaceae.) is colourless, pale yellow or amber brown and is only about $10 \%$ soluble in water
(Anonymous, 1985). The gum is collected during autumn from the trunk and larger branches. It is also described as the salt of acidic polysaccharide, in which acid groups are neutralized by calcium, potassium and iron (Nussinovitch, 2009). The gum exudates of almond tree constitute $2.45 \%$ of protein $0.85 \%$ of fats and $92.36 \%$ of carbohydrates on a dry weight basis. They are also rich in minerals such as Calcium, iron, potassium, sodium and magnesium (Mahfoudhi et al., 2012).

\section{Acaacia nilotica gum/ gum arabic}

Gum acacia is a complex polysaccharide, pale to orange brown colour either neutral in nature or slightly acidic; they are found as calcium, magnesium, and potassium salt of a polysaccharidic acid. It is $50 \%$ soluble in water. They are widely used as additives, thickeners or emulsifiers, and are also used to increase the stability. They are used as a binder in pharmaceutical industry. The gum exudates of gum Arabic contain 15.38\% of crude protein, $62.26 \%$ of carbohydrates and $1387.591 \mathrm{kcal} / \mathrm{kg}$ of energy. They also contain minerals such as calcium, potassium, magnesium, iron, sodium, manganese, zinc and phosphorous (Ogbe et al., 2012).

\section{Materials and Methodology}

Almond gum and gum Arabic have nutritional properties, and are produced naturally; they do not contain any synthetic chemicals. The resins are tested for its solubility, thermal stability, toxicity level and UV absorbance. The above analyses are performed to check if the resins can be coated on fruits for preservation. With respect to the feasibility of the sample based on the above test, sample's effect on fruits and vegetables can be observed by coating it on them. 


\section{Sample Collection}

Resins- Prunus amygdalus dulcis (sample 1) and Acacia nilotica (sample 2) were collected from an ayurveda shop in broadway.

\section{Solubility Test}

Almond gum and gum arabic was cleaned and 0.5 gram was taken in $5 \mathrm{ml}$ of distilled water, Dimethyl sulfoxide and methanol separately in three different test tubes. They were left undisturbed for 24hours.

\section{Sample Preparation}

Almond gum and gum Arabic are cleaned without any bark remains on them and are dried at about $50-60^{\circ} \mathrm{C}$ for 90 seconds in a microwave oven. The dried gums are powdered using a pestle and mortar.

\section{Extraction}

20 grams of the powdered test samples 1 and 2 were weighed and wrapped in a muslin cloth. The extraction process was carried out using soxhelet apparatus with $150 \mathrm{ml}$ of distilled water as the solvent for extracting the compounds. Apparatus was set and the soxhelet extraction was run. After the completion of three cycles the extract was collected and stored in the refrigerator for future use.

\section{Therogravimetry Analysis}

Thermo gravimetric analysis is used for characterizing the quantitative weight loses of the test sample. Their mass based on the temperature variations is obtained. The resins were loaded into the thermogravimetry instrument and run.

\section{Toxicity Analysis}

Toxicity tests are carried out using Artemia salina. The nauplius is tested against the extracts of almond gum and guar gum for 24hours, number of viable nauplii is counted, and the death rate is calculated.

\section{Cyst Cultivation}

In a conical flask, $13 \%$ salt concentrated water is taken and to it, a pinch of cyst is added. The aerator is fixed inside the conical flask for aerating the cysts. The flask with cysts was left under the light for incubation.

\section{Incubation and Assay}

The cysts started to hatch after 36hours. After hatching of the cysts, the nauplius were counted and transferred into two different test tubes containing test samples 1 and 2 respectively. It was allowed to incubate for 24hours under the light and the test results were noted.

\section{Coating on Fruits}

Fresh handpicked apples, oranges were bought from the nearest organic fruit shop and they were washed and dried.

Few grams of almond gum and gum Arabic were boiled in water and were completely melted. The melted tree gums were applied on the fruits. Uncoated orange and apple were left as a control for observing the number of days, the fruits can withstand decay.

\section{Results and Discussions}

\section{Solubility test}

Almond gum and gum Arabic were tested for its solubility in various solvents such as Methanol, Dimethylsulfoxide, and distilled water. It was seen that Gum Arabic dissolved partially in distilled water and Dimethylsulfoxide, but did not dissolve in methanol. While, Almond gum dissolved 
little in distilled water and was swollen. It did not dissolve in methanol and Dimethylsulfoxide.

\section{Thermal Analysis of Almond Gum and Gum Arabic}

Thermo gravimetric analysis is physical tool to monitor the physical and chemical changes of the polysaccharide during thermal processing.

The curve in graph 1(a) gives the details of thermal behaviour and thermal stability data. According to the primary thermogram for the gum show that heating at a rate of $20{ }^{\circ} \mathrm{C}$ per min from $0{ }^{\circ} \mathrm{C}$ to a max of $800{ }^{\circ} \mathrm{C}$ it is seen that there is a early minor weight loss of about $9.40 \%$ at $131.21^{\circ} \mathrm{C}$ which is due to the loss of structural water the biopolymer sample. The second stage of weight loss of about $16.1 \%$ has taken place at $273.03^{\circ} \mathrm{C}$. The decomposition phase starts from there on and the decrease in weight loss percentage is $36.60 \%$ at $354.91^{\circ} \mathrm{C}$. The last phase of weight loss of about $46 \%$ occurs at $676.65^{\circ} \mathrm{C}$

The curve in graph 1(b) gives the details of thermal behaviour and thermal stability data. According to the primary thermogram for the gum show, that heating at a rate of $20{ }^{\circ} \mathrm{C}$ per min from $0{ }^{\circ} \mathrm{C}$ to a max of $800{ }^{\circ} \mathrm{C}$ it is seen that there is a early minor weight loss of about $6.17 \%$ at $157.03^{\circ} \mathrm{C}$ which is due to the loss of structural water the biopolymer sample. The second stage of weight loss of about $12.83 \%$ has taken place at $280.61^{\circ} \mathrm{C}$. The decomposition phase starts from there on and the decrease in weight loss percentage is $40.13 \%$ at $367.04^{\circ} \mathrm{C}$. The last phase of weight loss of about $48.43 \%$ occurs at $628.611^{\circ} \mathrm{C}$

\section{Toxicity Test}

$1 \mathrm{ml}$ of $13.33 \%$ of almond gum and gum Arabic extracts were dissolved in $10 \mathrm{ml}$ of saline water separately. To it, ten nauplius of Artemia salina were added and left for incubation for about 24hours. After 24hours, number of dead nauplius was counted and the mortality rate was calculated.

\section{Fruit coating}

The melted almond gum and gum Arabic were coated on apples, oranges and tomatoes and were observed along with the control ones (uncoated fruits). The results are as follows:

Table.1 Results of toxicity analysis

\begin{tabular}{|l|c|c|c|c|c|}
\hline Extract & $\begin{array}{l}\text { Final } \\
\text { concn. } \\
(\%)\end{array}$ & $\begin{array}{l}\text { Total No: } \\
\text { of Nauplii }\end{array}$ & $\begin{array}{l}\text { No: of } \\
\text { Alive }\end{array}$ & $\begin{array}{l}\text { No: of } \\
\text { Dead }\end{array}$ & $\begin{array}{l}\text { Mortality Rate } \\
\text { (Percentage) }\end{array}$ \\
\hline Almond gum & 1.3 & 10 & 10 & 3 & 0 \\
\hline Gum arabic & 1.3 & 10 & 9 & 4 & 10 \\
\hline
\end{tabular}


Fig.1 Prunus amygdalus dulcis gum coated fruits, Uncoated fruits and Acacia nilotica gum coated fruits of Day 0.

Prunus amygdalus dulcis gum coated Apple, Orange, Tomato - Day 0

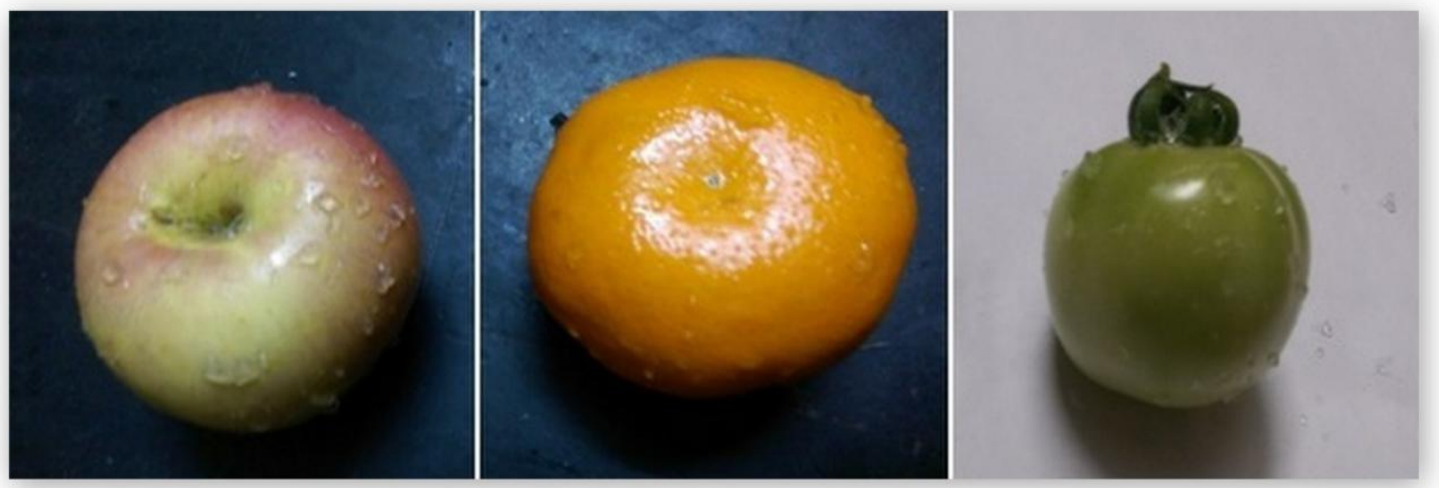

Uncoated Apple, Orange and Tomato - Day 0
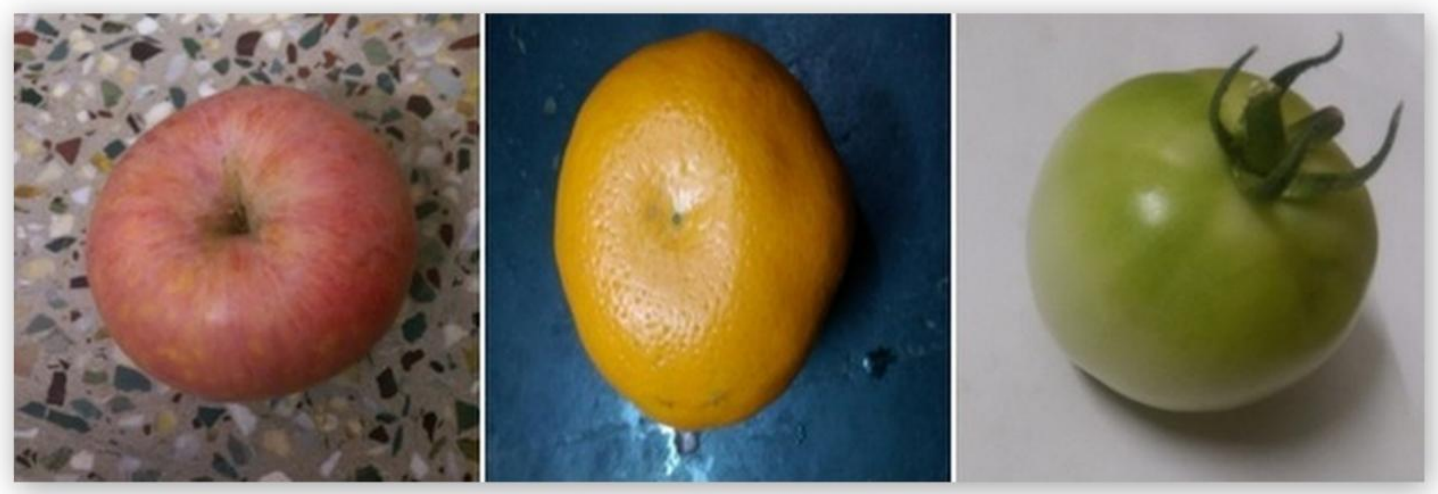

Acacia nilotica gum coated Apple, Orange and Tomato- Day 0

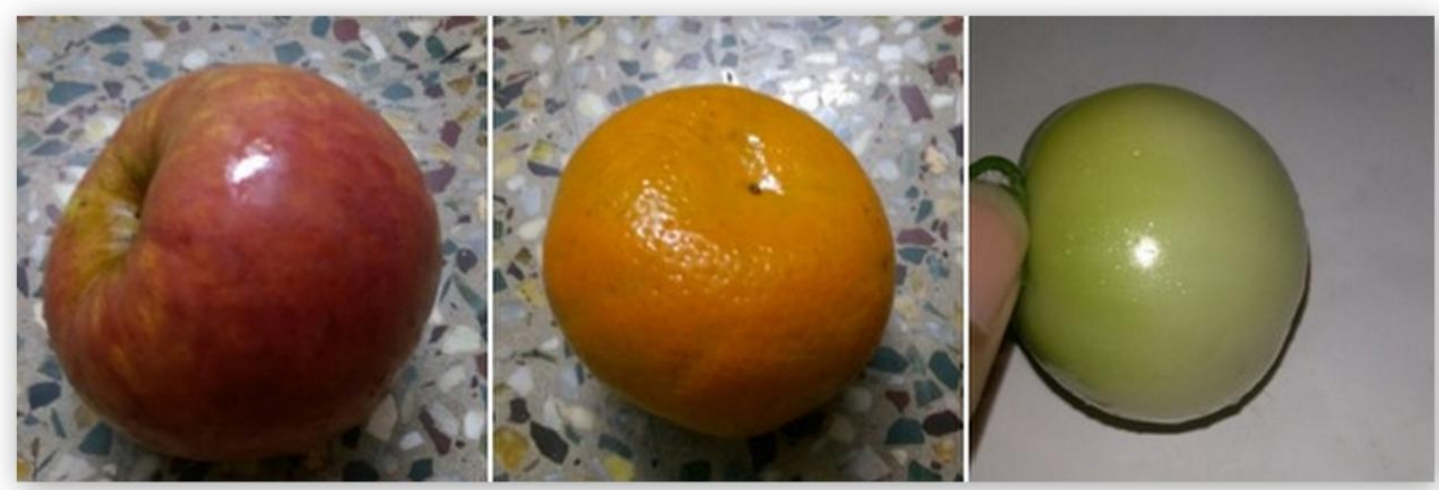


Fig.2 Uncoated Orange, Apple and Tomato's decay on their respective days

\section{UNCOATED ORANGE, APPLE AND TOMATO}
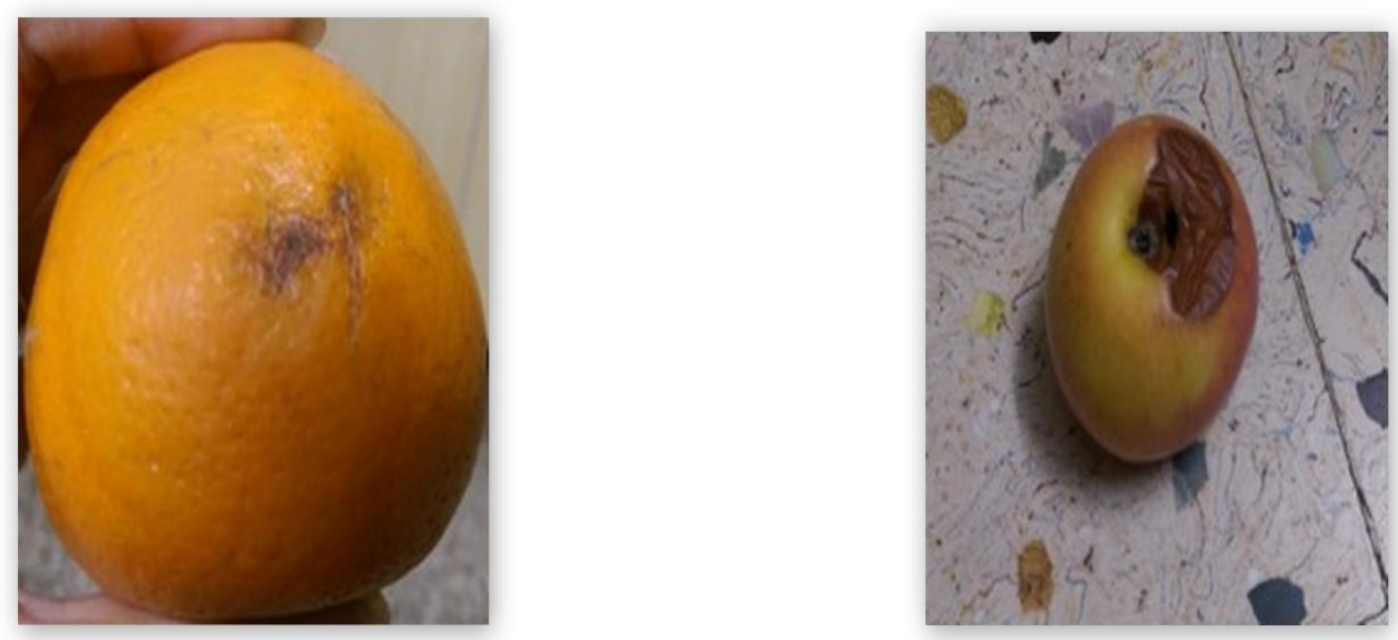

DAY 2

DAY 8

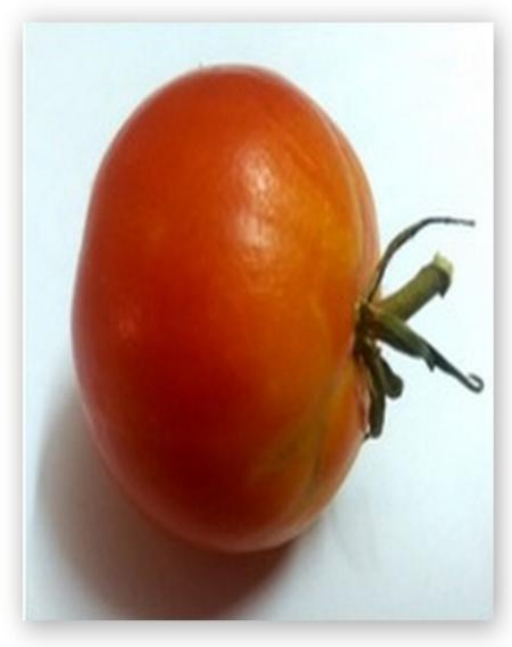

DAY 15 
Fig.3 Acacia nilotica gum coated Orange, Apple and Tomato's decay on their respective days.

Acacia nilotica gum coated Orange, Apple and Tomato

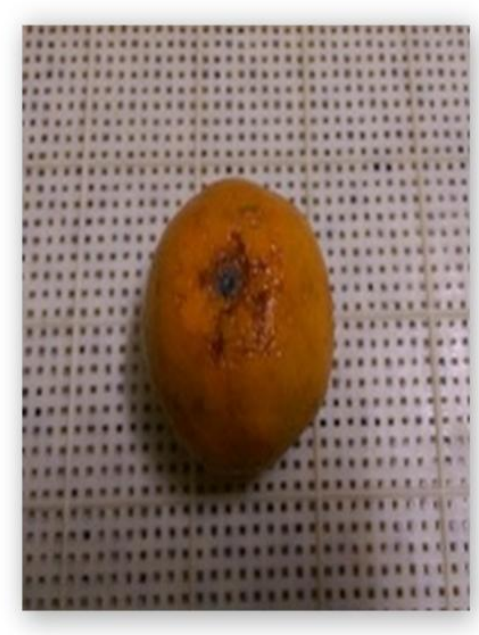

DAY 12

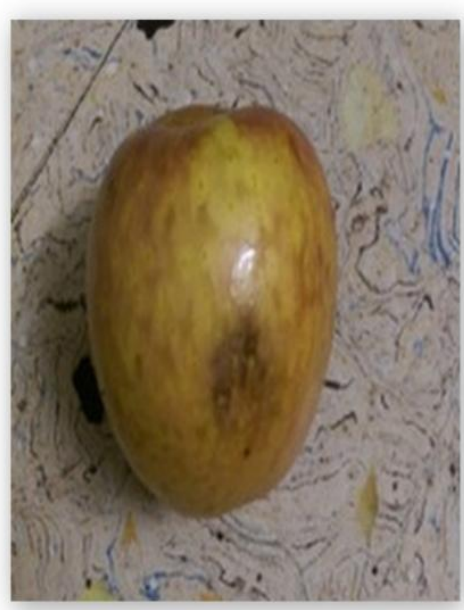

DAY 15

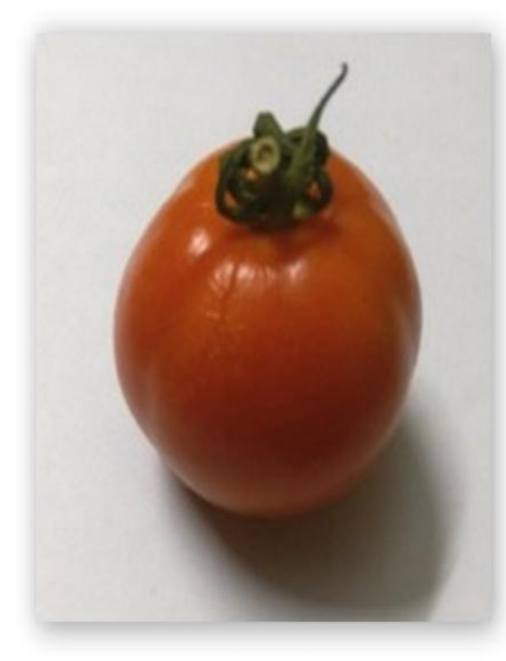

DAY 24 
Fig.4 Prunus amygdalus dulcis gum coated Orange, Apple and Tomato's decay on their respective days.

Prunus amygdalus dulcis gum coated Orange, Apple and Tomato

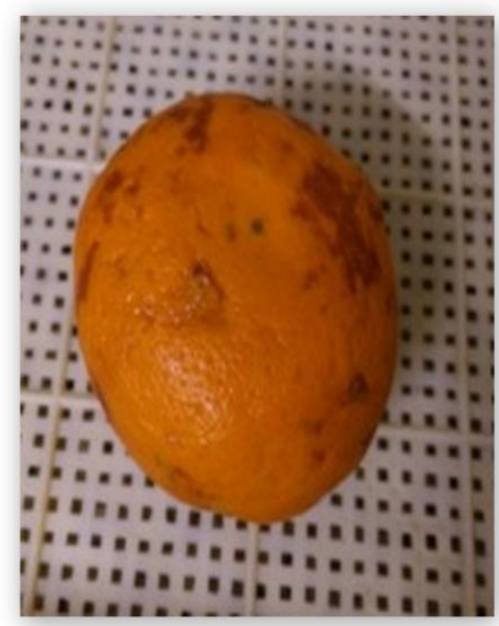

DAY 24

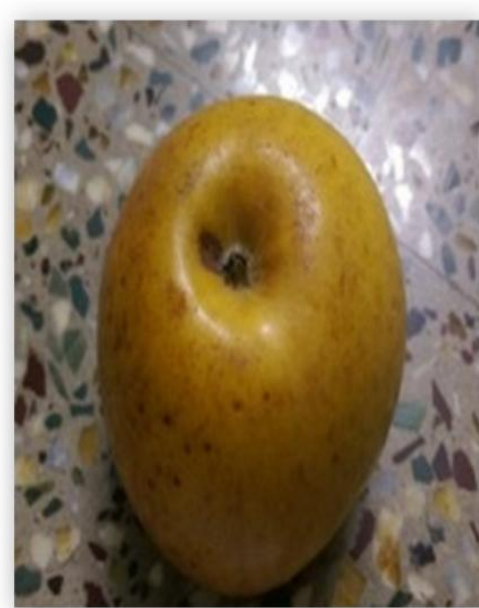

DAY 46

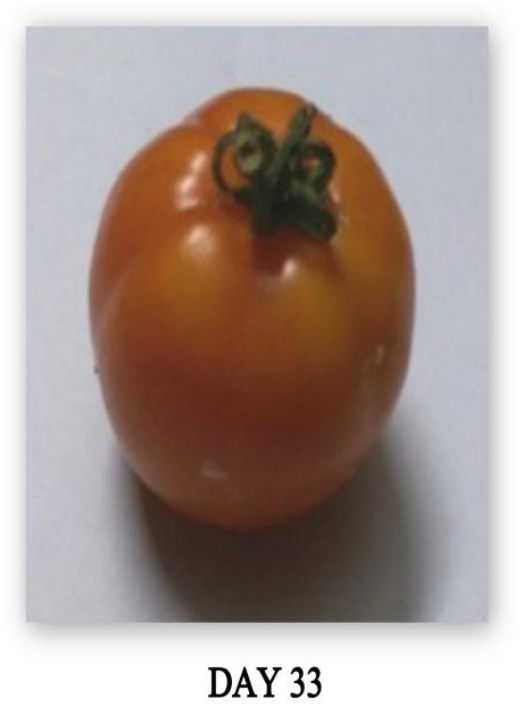


Graph.1 (a) - TGA curve of almond gum Graph 1(b) - TGA curve of Gum Arabic.

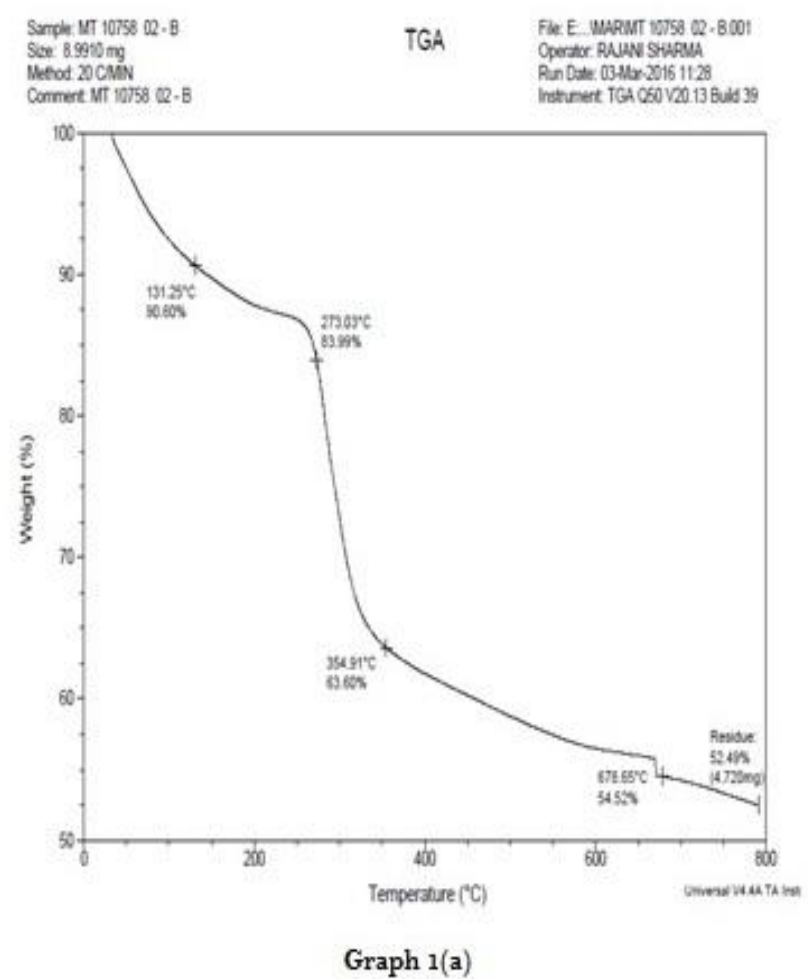

\section{Summary and Conclusion}

The project was carried out to study the effect of Prunus amygdalus dulcis gum/ almond gum and Acacia nilotica gum/ gum arabic on fruits such as apple and orange for increasing its shelf life. Thermal characteristics of almond gum and gum Arabic prove to be stable until $273^{\circ} \mathrm{C}$ and $281^{\circ} \mathrm{C}$ respectively. Almond gum possesses only about $16 \%$ weight loss by $273^{\circ} \mathrm{C}$ while, Gum Arabic loses $13 \%$ weight loss at $281^{\circ} \mathrm{C}$ (Graphs 1(a) and 1(b)), which may be due to structural water content or due to desorption of moisture. Toxicity analysis was performed with Artemia salina to check the toxic level of the resins- almond gum and gum Arabic. Almond gum showed 0\% mortality rate and Gum Arabic gave only $10 \%$ mortality rate (Table 1 ). Hence both gums are not toxic for consumption. Gum Arabic and Almond gum were coated on

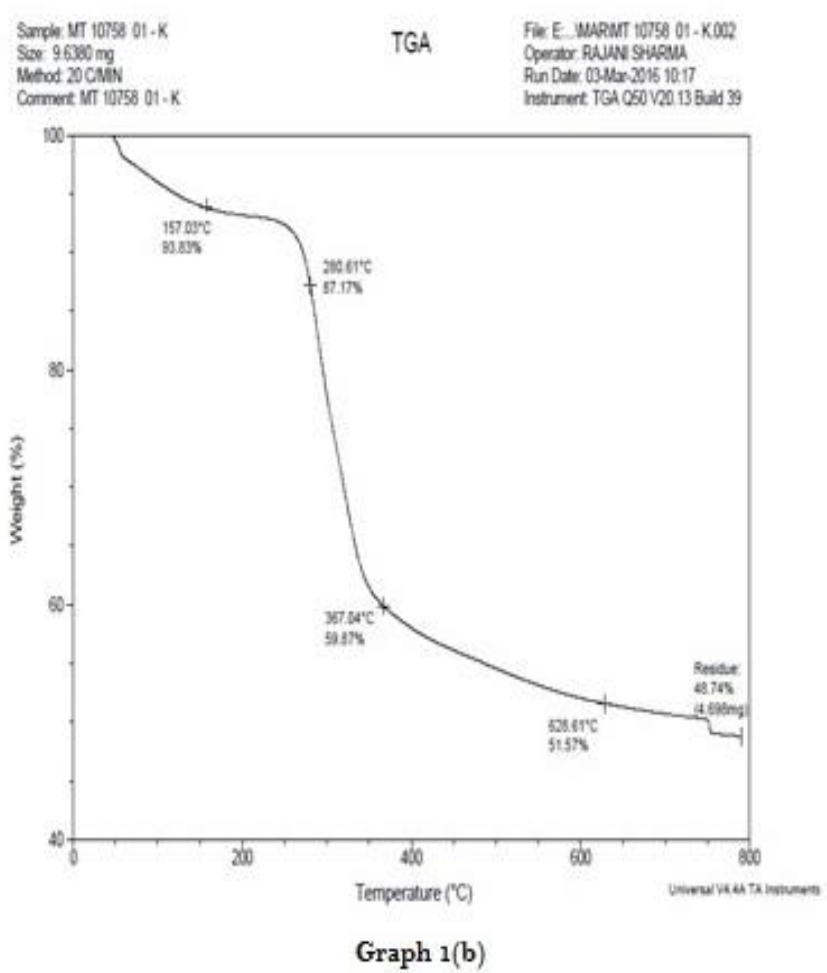

apples and oranges. Uncoated Orange and Apple were kept as control to check the feasibility of the resins (figures 1and 2). Apple coated with Almond gum (figures 1 and 4) and Gum Arabic (figures 1and 3) inhibited decay for about 46days, and 15 days respectively while the uncoated apple kept as control decayed by day 6. Orange coated with Almond gum and Gum Arabic inhibited decay for about 24days and 12days and started to undergo browning, while the uncoated orange started to decay by day 2 . The above results prove that fruits coated with Almond gum and Gum Arabic is safe for consumption and is efficient in enhancing its durability. Tomato coated with Acacia nilotica gum started to ripen early but it did inhibit decay for 24 days later the skin started to shrink, while the uncoated tomato's skin shrunk by day 15 . The tomato coated with Prunus dulcis delayed ripening and it enhanced its shelf life to 33 days. 


\section{References}

Adel, H., Bahnaswamy, Ei-Sayed, G., Khater. 2014. "Effect Of Wax Coating On The Quality Of Cucumber Fruits During Storage", Food Processing Technol., Vol. 5, Issue 6.

Ahvennainen, R. 1996. New approaches in improving the shelf life of minimally processed fruits and vegetables. Trends Food Sci. Technol., 7: 179187.

Anon, M.I. 1991. Food Irradiation - A technique for preserving and improving the safety of Food, WHO, Geneva.

Anonymous. 1985. Wealth of India: raw materials. Vol. VIII. New Delhi: Council for Scientific and Industrial Research.

Baldwin, E.A., Nisperos, M.o, Chen, X., \& Hagenmaier, R.D. "Improving storage life of cut apple and potato with edible coating". Postharvest Biol. Technol., 9: 151-163.

Behall, K.M. 2000. Whole food. J. American College of Nutri., 19(1): 6170, PMID 10682877.

Brown, M.E. 1998. "Introduction to Thermal Analysis, Techniques and applications.

Daniel, M. 2000. "Reactions to Food Additives and Preservatives.

Hassan, Z.H., Lasmayati, S., Qomariah, R., Hasbianto, A. 2014. "Effect Of Wax Coating Applications And Storage Temperatures On The Quality Of Tangerine Citrus(Citrus Reticulata) Var. Siam Banjar", Int. Food Res. J., Vol. 21(2).

Heldman, E.R. 1994. Frozen Foods: Challenges for the future, Food Australia, 45(8): 374-380.

James, L., Daft. 2003. Fumigants and related chemicals in foods: Review of residue findings, contamination sources, and analytical methods.

Jean, H., Langenheim. 2003. Plant resins.

Jean, P.B. 1994. Food Preservation. Nicolas Appert inventeur at humaniste, 2908670-17-8 and http://www.appert aina.com.

John, E.M. 1766. "Ionizing Radiations Sources, Biological Effects Emission and Exposures" 83.

Kathleen Riggs. 2011. "Food Sense Guide to Eating Fresh Fruits and Vegetables" In Food Sense - Utah State University.

Kolattukudy, P.E. 1984. "Natural Waxes on Fruits" in Post Harvest Pomology Newsletter, Vol.2, No.2.

Mahfoudhi, N., Chouaibi, M., Donsi, F., Ferrari, G., Hamdi, S. 2012. "Chemical Composition And Functional Properties Of Gum Exudates From The Trunk Of Almond Tree(PrunusDulcis) ", Food Sci. Technol. Int., Vol. 18(3).

Margaret Barth, Thomas, R., Hankinson, Hong Zhuang, Frederick Breidt. "Microbiological spoilage of fruits and vegetables".

Maria Alejandra Rojas-Grau, Robert SolivaFortuny, Olga Martin-Belloso. 2009. "Edible Coatings To Incorporate Active Ingredients To Fresh-Cut Fruits: A Review", Trends In Food Sci. Technol., Vol. 20, 2009

Muhammad Nasir, Shahid, Nadeem Akthar Abbasi. 2011. "Effect Of Bee Wax Coatings On Physiological Changes In Fruits Of Sweet Orange Cv."Blood Red, Sarhad J. Agric., Vol.27, No.3."Edible Coatings for Ready-ToEat Fresh Fruits and Vegetables", Phys.Org, 10 ${ }^{\text {th }}$ September 2013.

Nacheva, I., Miteva, D., Todorov, Y., Loginovska, K., Svetkov, T. 2012. "Modern High Technology Solutions For Quality And Long Term 
Vegetable Preservation", Bulgarian J. Agri. Sci., Vol. 18(2).

Nussinovitch, A. 2009. Plant gum exudates of the world: sources, distribution, properties and applications. London: CRC Press; p. 229-230.

Ogbe, A.O., John, P., Affiku. 2012. "Effect Of Polyherbal Extracts(MoringaOleifera, Gum Arabic \& Wild GanodermaLucidium) In Comparison With Antibiotic On Growth Performance And Haematological Parameters Of Broiler Chickens" Res. J. Recent Sci., Vol. 1(7): 10-18.

Paisan Loaharanu, Mainuddin Ahmed. 2011. "Advantages and Disadvantages of the use of irradiation for Food preservation". J. Agri. Environ. Ethics, Puneet Gupta, Neelam Singh, RlKhosa, Pandurangan, A., Giriraj, T., Kulkarni. 2014. "Structural Characterizatiuon Of Gum Exudate From Prunus Amygdalus Dulcis Tree As Pharmaceutical Excipient" $J$. Chromother., Drug Delivery, Vol. 5, Issue 3 .
Sanjay Sharma. 2015. "Food Preservatives And Their Harmful Effects", Ijsrp,Vol. 5 , Issue 4.

Saulo, A.A. 1994. Sugars and Sweetners in Foods, Food Safety and Technology, Published by College of Tropical Agriculture and Human Resources, University of Hawai'l at manoa, FST16.

Sirisha Sonti. 2003. "Consumer Perception and application of edible coatings on fresh - cut fruits and vegetables" in Louisiana State university May 2003. http://www.indiastudychannel.com/res ources/146681-Principle-working-andapplications-of-UV-spectroscopy.aspx

Sunil, B., Bothara, Sudharshan Singh. 2012. "Thermal studies on natural polymer" in Asian Pacific Journal of Tropical Biomedicine.http://radchem.nevada.ed u/classes/chem455/lecture_22_thermal methods.html;

http://www.ami.ac.uk/courses/topics/0 140_pl/index.html

Tiverios $\quad$ Vaimakis. 1998. "Thermogravimetry or Thermogravimetric analysis",

\section{How to cite this article:}

Yuvaraj, D., B. Suvasini and Fouziya, R. 2016. Resins as a Preservative for Fruits and Vegetables. Int.J.Curr.Microbiol.App.Sci. 5(9): 120-130. doi: http://dx.doi.org/10.20546/ijcmas.2016.509.014 